\title{
Resumos de
}

Teses Homologadas Dezembro/2017Abril/2018 


\section{WALTER CEZAR NUNES}

Orientador: Prof. Dr. Milton Antonio Zaro

Coorientadora: Profa. Dra. Léa da Cruz Fagundes

Data: 25/08/2016

Local: Sala 329 - Auditório do PPGIE/CINTED

TESE: EMPREENDEDORISMO POR OPORTUNIDADE: OBJETO DE APRENDIZAGEM COM PROPOSTA METODOLÓGICA, DESENVOLVIDA À LUZ DA NEUROCIÊNCIA, PARA MELHORAR A PERFORMANCE NA CAPACIDADE DE IDENTIFICAR OPORTUNIDADES DE NEGÓCIOS

Resumo: Esta pesquisa, propondo uma metodologia auxiliar para a disciplina de empreendedorismo originou-se de uma análise mais amiúde ocorrida dentro da universidade, onde se questiona a falta de efetividade dos conteúdos programáticos e metodologias empregadas na educação empreendedora. De um modo geral as Instituições de Ensino Superior (IES), formam mais futuros empregados que empregadores. Várias instituições oferecem inúmeros cursos e disciplinas de empreendedorismo ou afins, mas continuam colocando no mercado cada vez mais jovens que irão competir à um posto de trabalho por não conseguirem ver o empreendedorismo como opção de carreira. Uma possível resposta estaria permeada por fatores identificados em estudos recentes que afirmam que é de suma importância entender melhor como funciona o cérebro dos empreendedores para que se possa oferecer metodologias mais assertivas. Para muitos autores o processo de descoberta de oportunidades de negócios é uma das principais características do comportamento empreendedor e entender como este processo ocorre no cérebro dele abriria novas perspectivas. Esta pesquisa, desenvolvida a partir de dois experimentos, busca contribuir no âmbito universitário com uma proposta metodológica para a disciplina de Empreendedorismo desenvolvida à luz da neurociência. No primeiro experimento, denominado de teste piloto, com o objetivo de verificar possíveis padrões nos clusters neurais dos empreendedores quando identificam uma oportunidade, foi realizado o Mapeamento Cognitivo Cerebral com o uso de eletroencefalograma em 14 indivíduos do sexo masculino, sendo sete "empreendedores estabelecidos" e sete não empreendedores. Os resultados dos testes mostraram que os mapas neurais dos empreendedores sugeriram que as áreas frontais direita e esquerda dos cérebros foram acionadas tanto no momento de descoberta de oportunidades quanto no momento de propensão a assumir riscos, enquanto os não-empreendedores mostraram organizações neurais bem distintas durante os dois momentos. Este resultado aliado a outros estudos realizados por pesquisadores de empreendedorismo levou ao segundo experimento: o desenvolvimento de uma proposta metodológica auxiliar, que melhorasse a performance de alunos no processo de identificação de oportunidades de negócios. Esta proposta metodológica, cerne deste estudo, foi apresentada em um objeto de aprendizagem denominado: MADE- 
PERFIO, Módulo Auxiliar para Disciplina de Empreendedorismo-Performance na Identificação de Oportunidades, um curso de 40 horas, direcionado para melhorar a performance do aluno na identificação de oportunidades. A pesquisa sobre a efetividade da metodologia oferecida através do Módulo foi feita com 45 professores de graduações e de pós graduações e com 58 alunos de pós graduação de diversas faculdades e universidades maranhenses. Através de um curso de capacitação os professores puderam acessar o objeto de aprendizagem, testar a metodologia proposta e desenvolver suas performances cujos resultados foram extremamente encorajadores. Em média, os professores submetidos à nova metodologia melhoraram em $21 \%$ suas capacidades em identificarem oportunidades de negócios. Com relação à metodologia apresentada através do MADE-PERFIO, 45\% classificaram com o conceito "ótimo" e 40\% com o conceito "muito bom". A metodologia foi apresentada aos alunos no formato de Módulo Auxiliar, pois todos declararam já ter tido contato com a disciplina de Empreendedorismo, mas ainda não haviam empreendido. A pesquisa com os alunos mostrou um acréscimo médio de $23 \%$ em suas capacidades de identificarem oportunidades e $65 \%$ deles classificaram como "excelente" a relevância do conteúdo.

Palavras-chave: Neurociência, MCC-Mapeamento Cognitivo Cerebral, Busca de Oportunidades, Empreendedorismo, Comportamento Empreendedor, MADE-PERFIO, Neurompreendedorismo.

\section{RAQUEL USEVICIUS HAHN}

Orientadora: Profa. Dra. Marie Jane Soares Carvalho

Coorientadora: Profa. Dra. Liliana Maria Passerino

Data: 15/12/2017

Local: Sala 329 - Auditório do PPGIE/CINTED

TESE: A DISTÂNCIA TRANSACIONAL E A ORGANIZAÇÃO DE CURSIS DE LICENCIATURA ONLINE

Resumo: Esta tese tem o intuito de aprofundar os estudos na área de formação de professores para educação básica na modalidade a distância, integrando a linha de pesquisa Ambientes Informatizados e Ensino a Distância. Foi investigada como se estabelece a distância transacional nas disciplinas pedagógicas dos cursos de licenciatura em EAD, a partir da análise dos operadores conceituais, como o diálogo, a estrutura do curso e a autonomia do aluno. A pesquisa on-line, a análise documental e o questionário foram os principais instrumentos de coleta de dados. Os resultados alcançados evidenciam a relevância da aplicação da teoria da distância transacional na organização dos cursos na modalidade a distância para a diminuição 
expressiva da distância pedagógica de modo que tanto os alunos, quanto professores e tutores se sintam pertencentes ao curso e avancem em suas aprendizagens. Destaca-se a relevância da variável estrutura do curso que proporciona a interação mais expressiva do aluno com o conteúdo.

Palavras-chave: Formação de Professores para educação básica. Teoria da Distância Transacional. Educação a Distância. Cursos de Licenciatura.

\section{ARMANDO JOÃO ZAVALA}

Orientadora: Profa. Dra. Margarete Axt

Coorientadora: Prof. Dr. Eliseo Berni Reategui

Data: 28/02/2018

Local: Sala 329 - Auditório do PPGIE/CINTED

\section{TESE: EXERCÍCIO DE CIDADANIA NA ESCOLA PÚBLICA MOÇAMBICANA APOIADO POR UM JOGO DIGITAL EDUCACIONAL: PROJETO CIVITAS}

Resumo: $O$ ensino e aprendizagem mediados por jogos digitais educacionais, quando integrados ao currículo de educação formal podem, além do desenvolvimento atencionalcognitivo, potencializar a construção de conhecimentos nas suas diversas nuances dialéticas (saber-saber, saber-ser e saber-estar), bem como promover a capacidade imaginativa, estimulando o exercício da cidadania. Partindo desta propositura, esta tese estuda a possibilidade concreta de inserir um jogo digital educacional de construção de cidades em uma disciplina de TIC da educação básica, apoiado pela metodologia ativa do Projeto Civitas, e voltada para o exercício da cidadania. Assim, o estudo questiona sobre que efeitos o jogo Città, integrado na proposta metodológica do Civitas pode produzir na formação de alunos para o exercício da cidadania, na disciplina de TIC de uma escola pública. A tese surge do questionamento do autor às práticas docentes no contexto de sala de aula no ensino secundário em Moçambique, instigada pela imersão do mesmo nas dinâmicas e vivências do grupo de pesquisa do Laboratório de Estudos em Linguagem, Interação e Cognição (LELIC/UFRGS), desde 2014, através da cooperação internacional do Projeto Civitas BrasilMoçambique. Metodologicamente, optamos por uma pesquisa intervenção, pelo viés de in(ter)venção, adotando uma abordagem dialógica, baseada no princípio de alteridade proposto por Bakhtin nas pesquisas em ciências humanas. Os enunciados advindos do diário de campo, software Multipoint Server 2011 e facebook, são considerados como inacabados por isso, foram colocados em inter-relação para a sua análise, tendo sido apreciados dentro do quadro referencial bakhtiniano, o que nos permitiu trabalhar a sua arquitetônica dialógica de "eu-para- 
mim, eu-para-o-outro, outro-para-mim", na perspectiva ato responsável. Os resultados da pesquisa dão pistas de que experimentações envolvendo jogos digitais educacionais de construção de cidades, apoiados pela metodologia ativa do Civitas quando voltados para o exercício da cidadania, possibilitam explorar problemáticas de cidades na perspectiva éticoestético-política, potencializando um viés interdisciplinar: debatendo tópicos diferentes, criticando e sugerindo algumas ações... Estas aprendizagens, possibilitam a formação de valores como cooperação, solidariedade, reciprocidade, capacidade expressiva e de escuta, para além da construção de conhecimentos.

Palavras-chave: tecnologias de informação e comunicação, jogos digitais educacionais, simulador Città, metodologia ativa dialógica, estudos bakhtinianos.

\section{ROCELI PEREIRA LIMA}

Orientadora: Profa. Dra. Magda Bercht

Coorientadora: Profa. Dra. Liliana Maria Passerino

Data: 07/03/2018

Local: Sala 329 - Auditório do PPGIE/CINTED

TESE: PROMOÇÃO DE INTERESSE EM CRIANÇA COM AUTISMO A PARTIR DE UMA PLATAFORMA EDUCACIONAL ASSISTIVA COM FANTOCHE ELETRÔNICO

Resumo: A tecnologia na sua evolução e transformação, influência novos desdobramentos da técnica, dos processos e de aplicações, não somente na indústria, mas também em processos sociais e culturais. Dentre essas, o uso de Tecnologia de Informação e Comunicação na Educação, Engenharia e de modelos da Computação Afetiva como recurso de ação mediadora para promoção do ser social. Neste contexto, a presente Tese desenvolveu, à luz da Teoria Sócio-Histórica, uma Plataforma Educacional Assistiva capaz de possibilitar a promoção do estado afetivo de interesse em crianças com Transtorno do Espectro Autista - TEA de anos iniciais do Ensino Fundamental. O TEA é um transtorno síndrome que apresenta déficit no desenvolvimento, em escala de grau de manifestação, nos domínios comportamental, comunicativo e ou cognitivo. O déficit na habilidade de "atenção conjunta", falta de reciprocidade emocional, a própria falta de interesse, e prejuízo qualitativo na comunicação verbal e não-verbal são características mencionadas largamente na literatura. Para "compensar" esse gap o professor (assim como pais e terapeutas) precisam enfrentar o desafio de projetar estratégias de interação que possam promover cenas de atenção conjunta. Além 
disso, segundo dados do censo de educação básica de 2015, das quase 8 milhões de matrículas na Educação Infantil, cerca de 900 mil são para Educação Especial, sendo 700 mil no Ensino Fundamental e o preocupante afunilamento para 30 mil no 9 ano do Ensino Médio. Esses números reafirmam a importância da inclusão social e acredita-se que este decréscimo esteja relacionado com a necessidade de um apoio tecnológico contextualizado nas atividades comunicativas não-linguística e de atenção conjunta, pois esses atrasos normalmente ocorrem entre 12 e 36 meses de vida do sujeito TEA. A metodologia de pesquisa é de natureza qualitativa e utilizou o método de estudo de caso, de múltiplos casos. A atividade educativa foi desenvolvida por meio da contação de história infantil e uso de recurso tecnológico, dispositivo robótico, de ação mediadora, denominado de Fantoche Eletrônico, especialmente projetado nesta pesquisa. A práxis teve como base sociocognitiva as três etapas de intenção comunicativa da aquisição da linguagem proposta por Tomasello. Os resultados analisados dos estudos de casos apontaram que o uso do Fantoche Eletrônico promoveu mais de $80 \%$ de cenas de atenção conjunta, e um aumento de 3 casos positivos para quase 10, representado um ganho de mais de 200\%. Além disso, após a estratificação dos 96 dados, $83 \%$ apresentaram indicativo positivo de estado afetivo de interesse. A Plataforma Educacional Assistiva foi denominada de Asistranto e mostrou adequada para o desenvolvimento de diferentes atividades acadêmicas com o objetivo de incluir pessoas com deficiência em espaços escolares. O nome Asistranto é a tradução da palavra "assistência" na língua Esperanto.

Palavras-chave: Estado Afetivo de Interesse. Teoria Sócio-Histórica. Plataforma Educacional Assistiva. Fantoche Eletrônico. Autismo. 